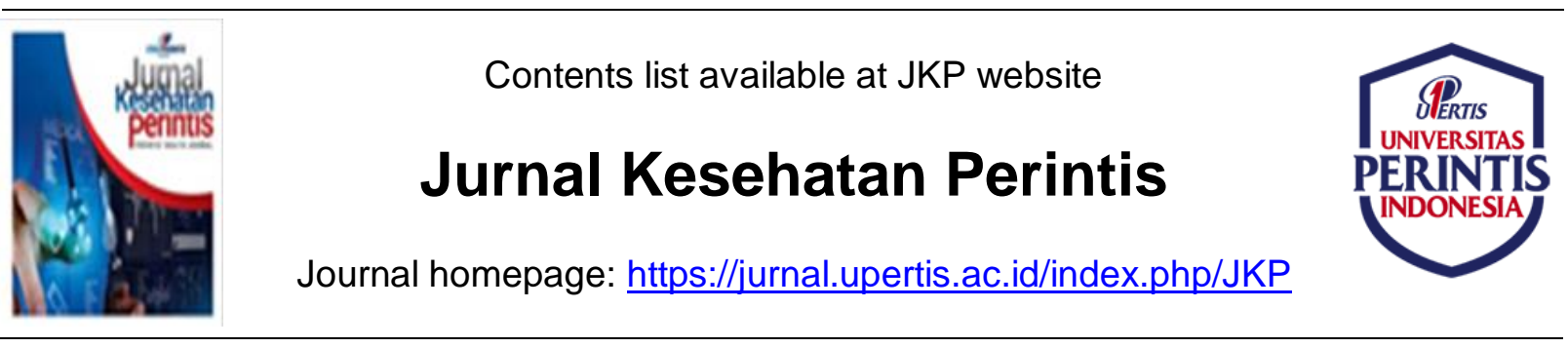

\title{
Academic Burnout pada Proses Pembelajaran Daring
}

\author{
Rima Novianti \\ Program Studi Sarjana Keperawatan, STIKes Horizon, Jawa Barat, Indonesia
}

\section{Article Information :}

Submission: Oct 06, 2021; Revised:Nov 23, 2021; Accepted:Dec 28, 2021; Available online: Dec 31,2021

*Corresponding author : rima.novianti.krw@horizon.ac.id

\begin{abstract}
ABSTRAK
Academic burnout mengacu pada stress dan faktor psikologis karena proses pembelajaran sehingga menunjukan keadaan kelelahan emosional, kecenderungan untuk depersonalisasi dan perasaan prestasi yang rendah. Sindrom ini dapat mempengaruhi kompetensi mahasiswa dan perubahan fisik dan mental. Tujuan Penelitian ini untuk diketahuinya academic burnout pada pembelajaran daring. Jenis penelitian ini menggunakan cross sectional, populasi pada penelitian adalah mahasiswa STIKes Horizon yang telah melakukan proses pembelajaran daring selama1 tahun akademik, pengambilan sample menggunakan Snowball Sampling dan Simple Random Sampling dengan jumlah sampel 276 responden. Instrumen penelitian yang digunakan academic burnout dengan melihat nilai exhaustion, Cynicism dan professional efficacy. Korelasi exhaustion dengan Cynicism menunjukkan hubungan yang sangat lemah dan arah hubungan bernilai positif $(R=0.680)$, korelasi exhaustion dengan professional efficacy menunjukkan hubungan kuat dan arah hubungan bernilai negative $(R=-0.244)$, korelasi Cynicismdengan professional efficacy menunjukkan hubungan kuat dan arah hubungan negative $(R=-0.311)$, dapat disimpulkan bahwa dimensi exhaustion, Cynicism dan professional efficacy saling mempengaruhi pada academic burnout, hal ini diperkuat dengan ditemukan data mayoritas mahasiswa merasa lelah 155 (56.2\%), memiliki perasaan sinis 137 (49.6\%) dan merasa tidak kompeten dengan proses pembelajaran 140 (50.7\%). Saran, Untuk meningkatkan efek positif dan mencegah insiden academic burnout di kalangan mahasiswa, dianjurkan untuk melakukan perubahan strategi pembelajaran dan berinovatif, Penelitian ini dapat juga menjadi dasar bagi pengelola untuk dapat melakukan perubahan strategi pembelajaran yang inovatif pada saat pembelajaran daring.
\end{abstract}

Kata kunci: Academic burnout, cynism, exhaustion, professional efficacy

\section{ABSTRACT}

Academic burnout refers to stress and psychological factors due to the learning process that indicate exhaustion, Cynicism and professional efficacy. This syndrome can affect student competence and physical and mental changes. The purpose of this research is to know the academic burnout in online learning. This type of research uses cross sectional, the population in the study is a student of STIKes Horizon who has conducted an online learning process for one academic year, sampling using Snowball Sampling and Simple Random Sampling with a sample number of 276 respondents. Research instruments used academic 
burnout with look the values of exhaustion, Cynicism and professional efficacy. The correlation of exhaustion with Cynicism indicates a very weak relationship and the direction of the positive value relationship $(R=0.680)$, correlation of exhaustion with professional efficacy indicates a strong relationship and the direction of negative value relationships $(R=$ -0.244), correlation of Cynicism with professional efficacy showing strong relationships and negative relationship directions $(R=-0.311)$, it can be concluded that the dimensions of exhaustion, Cynicism and professional efficacy influence each other in academic burnout, this is reinforced by the data of the majority of students feeling tired 155 (56.2\%), having cynical feelings 137 (49.6\%) and feeling incompetent with the learning process 140 (50.7\%). To increase positive effects and prevent incidents of academic burnout among students, it is recommended to make changes in learning and innovative strategies. This research can also be the basis for managers to be able to make innovative learning strategy changes during online learning.

Keywords: Academic burnout, cynism, exhaustion, professional Efficacy

\section{PENDAHULUAN}

Penyebaran Coronavirus Disease (Covid-19) mendorong pemerintah untuk mengeluarkan beberapa kebijakan, salah satunya adalah kebijakan belajar dari rumah. Kebijakan ini bertujuan untuk membatasi jarak antar individu (social distancing) sehingga penyebaran Covid-19 dapat ditekan (Alfarizi, 2021; Handayani et al., 2020; World Health Organization, 2021). Mahasiswa dan dosen dapat melakukan kuliah secara daring tanpa dibatasi tempat dan waktu, tetapi bukan tidak mungkin mengalami kesulitan untuk menangkap materi karena ada beberapa gangguan yang terjadi selama kuliah daring (Kementrian Pendidikan dan Budaya, 2020). Salah satu dampak yang terjadi pada proses pembelajaran daring, yaitu academic burnout.

Academic burnout dapat didefinisikan sebagai reaksi emosional, fisik, dan mental negatif terhadap studi berkepanjangan yang mengakibatkan kelelahan, frustrasi dan kurangnya motivasi. Academic burnout mengacu pada stress, beban atau faktor psikologis lainnya karena proses pembelajaran yang diikuti mahasiswa sehingga menunjukan keadaan kelelahan emosional (exhaustion), kecenderungan untuk depersonalisasi (cynism), dan perasaan tidak kompeten (professional efficacy) (Maslach \& Leiter, 2016).

Dimensi exhaustion, mengacu pada perasaan lelah. Dimensi ini mengarah pada perasaan emosional yang berlebihan dan perasaan terkurasnya sumber daya emosional. Dimensi cynism, mengacu pada ketidakpedulian atau sikap menjauh terhadap perkuliahan yang dijalani. Dimensi profesional efficacy, mengacu pada sosial dan non-sosial dalam pencapaian akademik. Individu dengan skor rendah pada dimensi ini akan merasa tidak berdaya, merasa semua tugas yang diberikan berat (Adriaenssens et al., 2015; Ferri et al., 2015)

Tugas yang banyak dari aktivitas yang berbeda menyebabkan terjadinya permasalahan akibat harapan rasa damai dan tentram yang tidak didapatkan sehingga muncul rasa kelelahan fisik, psikologi dan frustasi dengan hasil yang tidak maksimal. Manajemen waktu yang buruk berdampak sulitnya menyusun skala prioritas, mana yang harus diselesaikan terlebih dahulu. Maka tidak heran dapat menimbulkan burnout pada mahasiswa.

Kelelahan emosional, rendahnya motivasi dan cyism dapat menghasilkan konsekuensi terhadap gangguan fisik dan mental seperti: gangguan tidur, gejala depresi dan gejala lainnya, lebih jauh lagi dapat mempengaruhi kinerja mahasiswa dalam melaksanakan praktik yang berisiko terhadap keselamatan pasien. Ketika mahasiswa sudah mulai frutasi dengan apa yang terjadi pada dirinya, maka rasa peduli terhadap lingkungan dan orang lain pun berkurang. Mahasiswa cenderung akan menutup diri dari dunia luar dan lebih jauh dapat berdampak pada krisis identitas atau quarter life crisis.

Hasil penelitian sebelumnya menyampaikan bahwa burnout sangat mungkin terjadi pada mahasiswa 
kesehatan, hal tersebut dapat terjadi karena penuhnya jadwal perkuliahan, praktek lapangan, tugas serta ujian (Wang et al., 2019). Penelitian ini ingin melihat gambaran dimensi burnout serta hubungan diantaranya pada proses pembelajaran daring. Tujuan Penelitian ini untuk diketahuinya academic burnout pada pembelajaran daring.

\section{METODOLOGI PENELITIAN}

Jenis penelitian ini adalah analitik observasional dengan desain studi cross sectional, penelitian dilakukan pada mahasiswa kesehatan. Tempat penelitian dilakukan di STIKes Horizon. Kriteria pada penelitian, mahasiswa STIKes Horizon yang telah mengikuti perkuliahan daring selama satu tahun akademik, peneliti menggunakan tehnik pengambilan sampel snowball sampling dan simple random sampling dan didapatkan 276 responden. Peneliti menggunakan data primer yang diperoleh dari lembar kuesioner menggunakan google formulir. Penelitian ini menggunakan instrumen kuesioner data diri berupa jenis kelamin, semester, program studi serta kuesioner academic burnout yang didapatkan dari penelitian sebelumnya yang dilakukan di Universitas YARSI tahun 2020 (Arlinkasari, 2020). Academic burnout menilai dimensi exhaustion sebanyak 5 pernyataan, Cynicismsebanyak 4 pernyataan, professional efficacy sebanyak 6 pernyataan. Penilaian academic burnout menggunakan opsi jawaban $0=$ tidak pernah, 1 = hampir tidak pernah, 2 = jarang, 3 = kadang-kadang, $4=$ sering, $5=$ sering sekali, $6=$ selalu. Analisa data univariat menggunakan nilai frekuensi serta analisa data untuk menilai factor yang dominan terkait dengan kejadian academic burnout menggunakan korelasi pearson.

\section{HASIL DAN PEMBAHASAN}

Pada tabel 1. dapat dilihat bahwa jumlah responden berdasarkan jenis kelamin laki-laki dan perempuan sebanyak 138 (50\%) responden, berdasarkan semester mayoritas semester 5 sebanyak $87(32 \%)$ responden, berdasarkan program studi mayoritas S1 keperawatan sebanyak $171(62 \%)$ responden. Pada tabel 2. dapat dilihat bahwa responden merasa lelah 155 (56.2\%) pada proses pembelajaran daring, tidak memiliki perasaan sinis 137 (49.6\%) responden, merasa tidak kompeten 140 (50.7\%) responden.

Pada Tabel 3. menunjukkan korelasi exhaustion terhadap Cynicismdidapatkan nilai $p$ value $0,000 \quad(<0.05)$ dengan arah hubungan bernilai positif (0.680), hal ini menunjukkan penurunan tingkat exhaustion diikuti dengan kenaikan cynism. Korelasi exhaustion terhadap professional efficacy didapatkan nilai $\mathrm{p}$ value $0,000 \quad(<0.05)$ dengan arah hubungan bernilai negatif (0.244), hal ini menunjukkan peningkatan tingkat exhaustion diikuti penurunan professional efficacy. Korelasi Cynicismterhadap professional efficacy didapatkan nilai $\mathrm{p}$ value $0,000 \quad(<0.05)$ dengan arah hubungan bernilai (-0.311), hal ini menunjukkan peningkatan tingkat

Table 1. Karakteristik Responden ( $\mathrm{N}=276)$

\begin{tabular}{lcc}
\hline \multicolumn{1}{c}{ Variabel } & f & $\%$ \\
\hline Jenis Kelamin & & \\
Laki-laki & 138 & 50 \\
Perempuan & 138 & 50 \\
Semester & & \\
Semester 1 & 39 & 14 \\
Semester 3 & 80 & 29 \\
Semester 5 & 87 & 32 \\
Semester 7 & 70 & 25 \\
Program Studi & & \\
Ners & 39 & 14.1 \\
S1 Keperawatan & 171 & 62.0 \\
D3 Keperawatan & 42 & 15.2 \\
D3 Kebidanan & 24 & 8.7 \\
\hline
\end{tabular}

Table 2. Distribusi Frekuensi Dimensi Academic burnout ( $\mathrm{N}=276)$

\begin{tabular}{lcc}
\hline \multicolumn{1}{c}{ Variabel } & $\mathbf{f}$ & $\%$ \\
\hline Exhaustion & & \\
Merasa Lelah & 155 & 56.2 \\
Tidak Merasa Lelah & 121 & 43.8 \\
$\begin{array}{l}\text { Cynism } \\
\text { Memiliki Perasaan }\end{array}$ & 139 & 50.4 \\
Sinis & 137 & 49.6 \\
Tidak Memiliki & & \\
Perasaan Sinis & & \\
$\begin{array}{l}\text { Professional Efficacy } \\
\text { Merasa Tidak }\end{array}$ & & \\
Kompeten & 140 & 50.7 \\
Merasa Kompeten & 136 & 49.3 \\
\hline
\end{tabular}


Jurnal Kesehatan Perintis 8 (2) 2021: 128-133

Table 3. Korelasi Dimensi Academic Burnout Pada Proses Pembelajaran Daring

\begin{tabular}{llcc}
\hline \multicolumn{1}{c}{ Variabel 1 } & \multicolumn{1}{c}{ Variabel 2 } & r & P value \\
\hline Exhaustion & Cynism & 0.680 & 0.000 \\
Exhaustion & Professional Efficacy & -0.244 & 0.000 \\
Cynism & Professional Efficacy & -0.311 & 0.000 \\
\hline
\end{tabular}

Cynicism diikuti dengan penurunan professional efficacy. Academic burnout adalah perasaan lelah karena tuntutan studi dan sikap terpisah atau menjauhi sekolah dan perasaan tidak kompeten (professional efficacy) sebagai seorang mahasiswa. Dimensi exhaustion mengacu pada perasaan lelah lain (Adriaenssens et al., 2015).

Dimensi Cynicism ditandai dengan ketidakpedulian atau sikap menjauh terhadap perkuliahan yang dijalani, tidak harus dengan orang sekolah. Dimensi profesional efficacy meliputi aspek sosial dan non-sosial dalam pencapaian akademik (Ferri et al., 2015; Galdino et al., 2020)

Korelasi exhaustion terhadap Cynicism memiliki arah hubungan positif, bila individu merasakan peningkatan rasa lelah maka dapat meningkatkan perasaan sinis terhadap proses pembelajaran. Korelasi exhaustion terhadap professional efficacy memiliki arah hubungan negatif, bila individu merasakan peningkatan rasa lelah maka dapat menurunkan rasa kompeten (rasa percaya diri) terhadap keterampilan melakukan tindakan. Korelasi Cynicismterhadap professional efficacy memiliki arah hubungan negatif, bila individu merasakan peningkatan perasaan sinis dapat menurunkan rasa kompeten (rasa percaya diri) terhadap keterampilan melakukan tindakan. Sehingga academic burnout tidak dapat terlepas dari dimensi exhaustion, Cynicismdan professional efficacy (Maslach \& Leiter, 2016)

Kelelahan emosional adalah kualitas sentral dan manifestasi burnout. Academic burnout yang terjadi selama studi terjadi ketika individu tersebut merasa exhaustion, Cynicismdan professional efficacy pada saat pembelajaran yang dapat menyebabkan masalah dan merusak kinerja. (Ferri et al., 2015; Jackson et al., 2016; Wang et al., 2019). Emosi memainkan peran penting dalam kehidupan mahasiswa dengan membina atau menghambat keterlibatan akademik dan akhirnya, kesuksesan akademik. Regulasi emosi juga dinilai erat kaitannya dengan kesejahteraan dan keberhasilan fungsi. Strategi pengaturan emosi khusus dapat dibagi menjadi adaptif atau maladaptive, sesuai efeknya pada pengaruh, perilaku, dan kognitif (Bikar et al., 2018; Vinter et al., 2020)

Hasil penelitian sebelumnya, tingkat burnout akademik mahasiswa keperawatan dekat dengan median pada skala academic burnout, Cynicismditemukan meningkat seiring berjalannya tahun akademik. Faktor yang paling mempengaruhi adalah tak berdaya, Ketidakpastian dan kebingungan. Penelitian lainnya menunjukkan $6 \%$ siswa menghadirkan burnout tinggi, 36,3\% menghadirkan exhaustion yang tinggi, $37,7 \%$ menghadirkan Cynicismtinggi dan $28,2 \%$ menyajikan professional efficacy yang rendah. Faktor lainnya yang mempengaruhi adalah: tidak adanya aktivitas fisik; beban kerja mingguan $>24$ jam; kekhawatiran empati yang rendah (Galdino et al., 2020; Paro et al., 2019; Tomaschewski-Barlem et al., 2014; ValeroChilleron et al., 2019).

Karakteristik exhaustion dapat dikaitkan dengan penderitaan mengenai situasi yang menyedihkan. Korelasi terkuat yang ditemukan melibatkan professional eficacy, ketika professional eficacy meningkat, pencapaian pribadi cenderung meningkat dan rasa tidak percaya diri akan berkurang. Cynicismterhadap Proffesional efficacy memiliki korelasi negatif. Mempertimbangkan peran yang relevan dari kelelahan emosional dalam pengembangan burnout.

Academic burnout telah terjadi dilihat dari nilai dimensi exhaustion, Cynicismdan professional efficacy, serta telah terjadi hilangnya rasa percaya diri dalam kemampuan akademik, tidak mampu konsentrasi dalam menerima pelajaran, sering merasa kelelahan sekalipun cukup istirahat dan selalu bermasalah dalam manajemen waktu. Terjadinya academic burnout pada mahasiswa dapat terjadi 
dikarenakan kurangnya aktivitas fisik, tugas perkuliahan yang menumpuk karena sering ditunda.

Kerentanan mahasiswa terhadap burnout telah dilaporkan dalam beberapa penelitian. Stres yang dihasilkan cenderung lebih intens pada pemula, yang masih belum berpengalaman dan kurang percaya diri, dan dengan demikian kelelahan emosional dan kelelahan akan terkendali. Menurunkan tingkat academic burnout responden perlu untuk meningkatkan hormone endorphine, endorphin merupakan suatu hormone yang diproduksi oleh sistem saraf pusat dan kelenjar pituitari pada saat manusia merasa bahagia dan mendapat istirahat yang cukup. Meningkatkan hormone endorphine dapat dilakukan dengan: melakukan aktifitas fisik, luangkan waktu untuk kegiatan social, jauhi permasalahan/ berteman baik dengan teman sekelas, hindari menunda penyelesaian tugas dan dapat juga dianjurkan melakukan staycations, sesuai dengan anjuran kondisi saat ini untuk membatasi mobilisasi dan menjauhi kerumunan serta memberikan waktu pikiran untuk beristirahat

\section{KESIMPULAN}

Hasil penelitian, menunjukkan korelasi exhaustion terhadap Cynicismdidapatkan nilai $p$ value $0,000(<0.05)$ dengan arah hubungan bernilai positif $(0.680)$, korelasi exhaustion terhadap professional efficacy didapatkan nilai $\mathrm{p}$ value $0,000 \quad(<0.05)$ dengan arah hubungan bernilai negatif (0.244), korelasi Cynicismterhadap professional efficacy didapatkan nilai $p$ value $0,000(<0.05)$ dengan arah hubungan bernilai $(-0.311)$

\section{REFERENSI}

Adriaenssens, J., Gucht, V. De, \& Maes, S. (2015). Determinants and prevalence of burnout in emergency nurses: a systematic review of 25 years of research. International Journal Of Nursing Studies, 52(2), 649-661. https://doi.org/doi:

10.1016/j.jinurstu.2014.11.004

Alfarizi, T. (2021). 5 M Dimasa Pandemi Covid 19 di Indonesia. PADK Kementrian Kesehatan. http://www.padk.kemkes.go.id/article/r ead/2021/02/01/46/5-m-dimasapandemi-covid-19-di-indonesia.html

Arlinkasari, F. (2020). Alat Ukur Academic Burnout.

https://www.researchgate.net/publicati on/340581755

Bikar, S., Marziyeh, A., \& Pourghaz, A. (2018). Affective Structures among Students and its Relationship with Academic Burnout with Emphasis on Gender. International Journal of Instruction, 11(1), 183-194.

Ferri, P., Guerra, E., Marcheselli, L., Cunico, L., \& Lorenzo, R. Di. (2015). Empathy And Burnout: An Analytic Cross-Sectional Study Among Nurses And Nursing Students. Acta BioMedica: Atenei Parmensis, 86(2), 104115.

https://mattioli1885journals.com/index. php/actabiomedica/article/download/47 92/3529

Galdino, M. J. Q., Almeida, L. P. B. M. de, Silva, L. F. R. da, Cremer, E., Scholze, A. R., Martins, J. T., \& Haddad, M. do C. F. L. (2020). Burnout Among Nursing Students: A Mixed Method Study. Investigacion $Y$ Educacion En Enfermeria, 38(1). https://doi.org/https://doi.org/10.17533/ udea.iee.v38n1e07

Handayani, D., Hadi, D. R., Isbaniah, F., Burhan, E., \& Agustin, H. (2020). Corona Viru Disease 2019. URNAL RESPIROLOGI INDONESIA, 40(2), 119-129.

Jackson, E. R., Shanafelt, T. D., Hasan, O., Satele, D. V, \& Dyrbye, L. N. (2016). Burnout And Alcohol Abuse/Dependence Among U.S. Medical Students. Acad Med, 91(9), 1251-1256. $\quad$ https://doi.org/doi: 10.1097/ACM.0000000000001138

Kementrian Pendidikan dan Budaya. (2020). Perkuliahan Dapat Dilakukan Tatap Muka dan Dalam Jaringan. Biro Kerjasama \& Hubungan Masyarakat Kemdikbud.

https://www.kemdikbud.go.id/main/blo g/2020/12/perkuliahan-dapatdilakukan-secara-tatap-muka-dandalam-jaringan-tahun-2021

Maslach, C., \& Leiter, M. (2016). Understanding The Burnout Experience: recent research and its 
implications for psychiatry. World Psychiatry, 15(2), 103-11. https://doi.org/doi: 10.1002/wps.20311

Paro, H. B. M. S., Sllviera, P. S. P., Perotta, B., Gannam, S., Enns, S. C., Giaxia, R. R. B., Bonito, R. F., Martins, M. A., \& Tempski, P. Z. (2019). Empathy Among Medical Students: Is There A Relation With Quality Of Life And Burnout? PLoS One, 9(4). https://doi.org/10.1371/journal.pone.00 94133

Tomaschewski-Barlem, J. G., Lunardi, V. L., Lunardi, G. L., Barlem, E. L. D., Silveria, R. S. da, \& Vidal, D. A. S. (2014). Burnout Syndrome Among Undergraduate Nursing Students In Public Universities. Revista LatinoAmericana de Enfermagem, 22(6), 934-941. https://doi.org/10.1590/01041169.3254.2498

Valero-Chilleron, M. J., Gonzalez-Chorda, V. M., Lopez-Pena, N., CerveraGasch, A., Suarez-Alcazar, P., \& Mena-Tudela, D. (2019). Burnout Syndrome In Nursing Students: An
Observational Study. Nurse Education

Today, 76, 38-43. https://doi.org/https://doi.org/10.1016/j. nedt.2019.01.014

Vinter, K., Aus, K., \& Arro, G. (2020). Adolescent Girls' And Boys' Academic Burnout And Its Associations With Cognitive Emotion Regulation Strategies. Educational Psychology. https://doi.org/10.1080/01443410.2020 .1855631

Wang, M., Guan, H., Li, Y., Xing, C., \& Rui, B. (2019). Academic Burnout And Professional Self-Concept Of Nursing Students: A Cross-Sectional Study. Nurse Education Today, 77, 27-31. https://doi.org/https://doi.org/10.1016/j. nedt.2019.03.004

World Health Organization. (2021). Weekly epidemiological update - 5 January 2021. WHO COVID-19 Epidemiological Updates. https://www.who.int/docs/defaultsource/coronaviruse/situationreports/20201012-weekly-epi-update9.pdf 